\title{
Leprosy Programmes in the Context of Endemic Disease Control*
}

\author{
S. G. BROWNE \\ Leprosy Study Centre, London, W.1.
}

\begin{abstract}
The present disillusionment regarding the general lack of success of most leprosy treatment programmes in effecting a progressive decline in incidence of the disease, makes imperative a critical examination of the methods adopted in various countries for dealing with the problem of leprosy. Local circumstances will determine the details of the best practicable plan, but economic and social factors must not be overlooked.
\end{abstract}

The time is ripe for a critical and objective reassessment of the effectiveness of leprosy programmes as part of operational research into the control of the major endemic diseases. The main dangers are two: to underestimate, and to overemphasize the importance of the leprosy component of the total endemic disease problem. Health planners and physicians have to avoid the Scylla of neglect of leprosy and the Charybdis of exaggerating its seriousness. The general situation is, at present, far from satisfactory: existing knowledge is not being applied (Browne, 1968), and the best practicable plan for most countries has not yet been decided or put into action. Despite good results registered in some treatment programmes, control of leprosy seems as distant as ever.

Several reasons may be adduced for the growing disillusionment: the early enthusiasms for mass campaigns, based on the expectation of quick results from sulphone treatment, were ill-founded; experiences in Africa were not applicable to countries facing a leprosy problem different in many ways; insufficient attention was accorded to the social component of leprosy; the population explosion in countries of high prevalence nullifies good efforts and exacerbates the problem. Premature attempts at the integration of leprosy programmes into general health programmes have proved illusory.

Certain inherent difficulties in leprosy control have not yet been adequately countered. Leprosy is but one of many morbidity-producing diseases in developing countries. Since its diagnosis may be difficult (and no easy test is available for mass screening), its treatment lengthy and of slow apparent effectiveness, and since the end-points of infectiousness and clinical cure are not easy to establish, the disease, not surprisingly, has generally a low priority and a high cost/effectiveness. Serious absenteeism and failure to take treatment for long enough, coupled with the concealment of infectious patients, have brought

\footnotetext{
* Paper given in the Leprosy Section of the International Congress of Tropical Medicine and Malaria, held in Athens in October, 1973.
}

Accepted for publication 6 November, 1973. 
well-conceived programmes into disrepute. Leprosy still suffers from the overenthusiastic and emotional advocacy of its friends, the prejudice of its enemies, the indifference of politicians and the ignorance of medical workers.

Because most leprosy programmes are primarily concerned with treatment, they lack such objective criteria as falling incidence rates. Moreover, since such programmes-for good historic or philanthropic reasons, as well as because of social prejudice-have mostly developed independently of measures adopted for the control of other endemic diseases, they have failed to profit from available epidemiological knowledge. Leprosy programmes today present a great range of diversity, reflecting as much a widespread uncertainty as a pragmatic adaptation to local needs and pressures:

(1) Segregation of all cases diagnosed, whatever the form or the infectiousness, has been practised in South Africa (Schulz and Pentz, 1970), Brazil, Japan (Yoshie, 1970) and Nepal. Selective segregation was adopted during the last century in Norway (Irgens, 1973), and nocturnal segregation has been attempted in certain areas in India. Where the prevalence rate is low, the population co-operative and adequate finance assured, the desirability of some kind of segregation cannot be a priori ruled out. The segregation practised in southern Europe, North Africa and the Near East is not for various reasons effective as a control measure.

Some francophone African countries are introducing temporary segregation of infectious patients "librement consenti" (Labusquiere, 1969).

The provision of units for the specialized care of sufferers from leprosy (as in U.S.A., Spain, England) is not to be regarded as segregation in the public health sense.

(2) The "segregation villages" of the former Eastern Nigeria and Uganda depended on the co-operation of patients and the traditional authorities, and the availability of land for farming. In the pre-sulphone days, the humane separation of patients from their communities for a time was followed by a considerable reduction in incidence of new cases of leprosy.

(3) A special leprosy service is provided where the population is dense, the prevalence high and the stigma serious.

In India, the S.E.T. (Survey, Education, Treatment) plan in the National Leprosy Control Programme is in operation in areas where the prevalence of leprosy is moderate; in hyperendemic zones, special Leprosy Control Units are advised. Altogether, some 968,053 patients are at present receiving treatment for leprosy (including voluntary agency programmes) out of an estimated number (1972) of 3.1 million.

In Ethiopia, a "market saturation" technique has been established with a clinic in each important market and smaller clinics at $10 \mathrm{~km}$ distance. Where, however, the population density is low, no separate leprosy service is provided (Browne, 1974).

Mobile clinics, which call at central villages at predetermined intervals, are assured by cyclists in francophone West Africa and by Land Rover in the LEPRA project in Malawi.

Foot patrols are necessary in the mountainous regions of Papua New Guinea. (4) A co

former Belgian Congo, where static dispensaries treated patients with leprosy as part of their polyvalent activities (Browne, 1972). 
(5) Combined programmes have not been widely adopted. Tuberculosis obviously lends itself to such a scheme, and the results in Zambia (McDougall and Drake, 1970) and the plans for central Malawi will bear examination and imitation elsewhere.

The French West Africa Service contre les Grandes Endémies has in some countries attempted to include leprosy in a programme that covers tuberculosis, trypanosomiasis, trachoma, etc. In the Philippines, leprosy is treated in "Skin Clinics", and in Thailand and parts of India, family planning clinics have been organized in conjunction with leprosy.

(6) "Auto-traitement", which consists of the provision of 6 months treatment for the patient, with opportunity for replenishment at the hands of a literate traditional leader (Nebout, 1972), seems the only practicable method of ensuring treatment where communications are poor (or non-existent for many months at a time), the population scattered, the general health services fragmentary, and the risk of serious leprosy reaction is low. Hence, good results are reported from Chad, Upper Volta, Niger and Senegal. It is also being tried, faute de mieux, in Nepal, where patients may have to walk for weeks over mountains to seek treatment.

In any measures taken for the control of leprosy, the following factors should be considered: the natural history of the leprosy endemic, the socio-economic status, the standards of oral, nasal and general hygiene, and the attitude of the population to the disease. The "felt needs" of leprosy patients (ulceration of extremities, deformities, stigmatizing conditions such as madarosis and wasting of the first interosseous space) should be recognized and met, otherwise measures related to control will not be accepted.

At present, BCG vaccination under certain conditions may enhance potential resistance, and dapsone prophylaxis may have a limited usefulness (Int. J. Lepr., 1973). A specific vaccine made from certain moieties of the cell-walls of the organism may become available from quantities of Myco. leprae present in the experimentally infected armadillo. Its use might stimulate an existing capacity to mount a cell-mediated immunity against leprosy challenge, and thus prevent tuberculoid leprosy developing with its consequential peripheral nerve damage. If it can also induce, in the individual without such a capacity the development of immunity, then the susceptibles will be protected and the incidence of new cases of multibacillary leprosy will be reduced to a trickle.

The most satisfactory way at present known of reducing incidence rates, however, is to render non-contagious all patients with multibacillary disease by means of standard treatment with bacteriostatic drugs. In addition, the treatment of patients with paucibacillary disease will reduce the possible dissemination from these patients of viable forms that may be non-stainable by ordinary techniques.

With many resources becoming available in poor developing countries for the prevention of measles, tetanus, smallpox, trachoma and trypanosomiasis, and the health teams working on nutrition, child welfare, malaria control, rehabilitation and family planning, it is not too much to expect that the grafting of approved leprosy treatment/control procedures on to such schemes will help to reduce costs, remove stigma, and bring leprosy within the purview of transmissible diseases that are diagnosable, treatable and controllable. Medical auxiliaries may need further training to make them polycompetent, and separate leprosy clinics will be absorbed into the larger service. The voluntary agencies have a continuing role to play in the new situation, bringing their financial help to research as well 
as to the service activities in which they have taken a leading part. With their initiative and flexibility, their concern for the social milieu of the leprosy sufferer, and their appreciation of the importance of health education, they may yet make a significant impact on the control of leprosy within the context of endemic disease.

\section{References}

Browne, S. G. (1968). Int. J. Lepr. 36, 544.

Browne, S. G. (1972). Lepr. Rev. 43, 16.

Browne, S. G. (1974). Lepr. Rev. 45, 78.

Int. J. Lepr. (1973). 41.

Irgens, L. M. (1973). Int. J. Epidem. 2, 81.

Labusquiere, R. (1969). Acta Leprol. 36, 5.

McDougall, C. A. and Drake, A. H. (1970). Lepr. Rev. 41, 15.

Nebout, M. (1972). Acta Leprol. 46-47, 135.

Schulz, E. J. and Pentz, H. H. L. (1970). Lepr. Rev. 41, 15.

Yoshie, Y. (1970). Lepr. Rev. 41, 9. 